and Twelve Cases of Convergent Squint, with Final Results of Operation; Amblyopia ex Anopsia ; Recurrent Oculo-motor Palsy ; Variations in the Power and in the Astigmatism of Thin Lenses in Oblique Centrical Refraction; Four Thousand Cases of Ocular Headache and the Different States of Refraction Connected Therewith; The Use of Strychnin in Insufficiency of the Interni; and a Note Concerning the Lens in the Eyes of Rodents. And these papers with the discussions upon them accupy 84 of the 214 pages of the transactions in question.

In the recent volume of the Transactions of the Section on Ophthalmology of the American Medical Association papers and discussions on similar subjects occupy 150 out of 350 pages, almost exactly the same proportion. But perhaps this charge of a lack on the part of American ophthalmologists of a proper respect for this part of their work, or of fear to avow it before European critics, is most completely met by the Transactions of the last International Ophthalmological Congress, held in Edinburgh. Of the ten papers of American authorship therein contained five are concerned with anomalies of refraction and muscle balance, and in the discussions on such subjects the small number of Americans present furnished two-thirds of the speakers.

The attack in question is equally uncalled for and unjustified whether it be regarded as against American ophthalmologists, or as against the American Ophthalmological Society, the only important rival of the Section on Ophthalmolology of the American Medical Association. One who has read the papers mentioned, and who can understand them, will recognize such expressions as "travesty of medical progress," or "caricature of conservatism," as inapplicable and absurd.

Of course it is impossible for one editor to prepare all the editorial columns of our great medical weekly, and I feel sure that you will not knowingly allow the use of those columns for the expression of private spleen or personal disappointment. Cordially yours, EDWARD JACKSON.

\section{Reply to the Article on Treatment of Aura Catarrh in the London Central Throat, Nose and Ear Hospital.}

To the Editor:-In No. 9, p. 411, of this Journal there is an article on "The Treatment of Aural Catarrh in the London Central Throat, Nose and Ear Hospital," that is liable to do harm, since it fortifies the position of the routinist, by allowing him to creep behind the walls of a large hospital. This article being typical of the standpoint of a great many physicians it would be treachery to let it pass without criticism.

Its author says: "I shall now proceed to make clear the method used for the cure of those varieties of ear disease, usually termed catarrh, and divided into acute non-suppurative, acute suppurative, chronic non-suppurative and chronic suppurative." Here the doctor undoubtedly speaks of the greatest number of those diseases that have their seat behind the drum, that is, in the middle and inner ear, and calls them "catarrh." What does that word catarrh mean? Where is the line clinically? Would it not be better to talk first about an accurate diagnosis? The writer speaks about the methods of "curing" them. When there is necrosis of the ossicles, or of the walls of the tympanic cavity, which I know from other men of this school are classed under the head of chronic suppurative catarrh, or when there are adhesions of the ossicles to those walls, which very often exist in those cases that they call chronic non-suppurative catarrh, did ever anybody see cures from the methods indicated? Cure means restoring, at least partly, normal and anatomical conditions and functions. It is not the purpose of these lines to show another way to reach that aim. For this there are text-books and papers, but I wish only to state that the way the article indicates will mislead.
The article correctly classes together acute suppurative and non-suppurative forms, but not because the one is a more severe form of the other. The reason for classing them together is that they are alike, the only difference being a perforation of the drum in one case, where this membrane is not so thick and offers less resistance. Pus is present in all ears afflicted with acute otitis media, as Bezold, Gradenigo and Knapp proved long ago.

The statement about adenoids is a matter of course, but I am thankful to the writer for giving this disease the place that is due to it. The subject of adenoids is not a fad of the specialists that will disappear again; but its high influence on the general condition, as well as on the special condition, of the surrounding organs, especially the ear, can not be overestimated. Because their removal is a nice and easy operation is not a reason why we should neglect it.

The paragraphs on chronic suppurative and non-suppurative catarrh have again the marks of routine treatment. I do not understand why, if such routine is adequate, those practical Englishmen should take doctors for such cures instead of nurses or intelligent waiters.

I think that the London Throat, Nose and Ear Hospital does not any longer occupy that standpoint. The days of the rou tinist in medicine are past; let them be past in otology, too. Let us start the reformation, however, in our own neighborhood. Let us instead study the conditions of each single case, then give it proper attention, and thus deserve the name of doctors and not treatment manufacturers.

Dr. J. HoLINGER,

Lecturer Post-Graduate Medical School; late Assistant Illinois Eye and Ear Infirmary.

\section{Death from Antitoxin.}

Wheelersburi, OHio, March 27, 1896.

To the Editor:--A most unfortunate and distressing accident occurred in the practice of Dr. S. S. Halderman, of Ports mouth, Ohio, on March 22, in connection with the use of antitoxin. A mild form of diphtheria was prevailing in the family of Mr. George Kricker, cashier of the Central Savings Bank, and the doctor administered the usual dose of antitoxin, as a prophylactic, to a little boy, 5 years old, in whom the disease had not yet appeared. The child, which had seemed to be in perfect health up to this time, was asleep when the injection was given, and in five minutes was a corpse. The doctor had withdrawn to another room to refill his syringe for use on another child, when the mother noticed the boy's lips puffing up and called to him that something was wrong with Willie. By the time the doctor reached the child, breathing had ceased. The killing fluid which thus acted with far more rapidity than a fatal dose of morphia, arsenic or strychnia given per mouth would have done, seems to have caused death by paralyzing the heart. At least that is the cause assigned in the death certificate. The serum was Behring's, fresh, injected beneath the scapula and in the usual way. The doctor, one of the the first to introduce antitoxin into medical practice in Portsmouth, was an enthusiastic advocate of serum therapy, and presumably used all the precautions which skill and experience can suggest. This terrible accident, therefore, can have but one meaning. It furnishes absolute proof of the inherent danger of antitoxin as a therapeutic agent.

Cautious scientific observers have insisted from the outset that a substance capable of acting on the economy with the alleged effects of antitoxin must necessarily be a powerful agent. Hence many conservative physicians have hesitated to employ the new remedy. The older men remember-aside from the new fads which have been constantly coming up how it was with chloroform forty years ago. The highest medical authorities then insisted that it was perfectly safe when 
administered with proper precautions. It was reported to have been used in 25,000 cases in the Crimean war and in 9,000 cases in St. Bartholomew's Hospital, without a single accident. Standard medical works sanctioned these reports. And no one will ever know how many deaths resulted from the recklessness engendered in the medical profession by this false attitude of the enthusiastic believers in chloroform.

So with antitoxin. Whatever may be the final verdict of the profession as to its merits as a remedy in diphtheria, the fact should not be lost sight of that it is a most powerful agent, that the contraindications to its use are not yet well ascertained, and that it can be an active instrument of great evil as well as possible good. It is not often that the evidence of the ill effects of an alleged remedy is as clear as it is in this case. Given as a prophylactic to a healthy child, disease can not be credited with any share of the result. No one can doubt that antitoxin kills, and that, too, right speedily. JAMEs L. TAYLOR, M.D.

\section{The A. M. A. Badge.}

Wilmore, PA., March 25, 1896.

To the Editor:---In a late number of the JournaL my attention was called to an article written by Dr. Stewart, of Detroit, Mich., as regards a permanent badge for the AMErican MEdical Association. The article comes in a good time and $\mathrm{I}$ have often wondered that as yet nothing has been done through the Journal, or at the yearly meetings of the Society, in the matter of choosing a badge for the Society, and am glad to see that Dr. Stewart has at last placed the matter so clearly before us as a Society. We surely know that the American MEDical Association has been founded nearly a half century and can venture on a badge when every order or society, great or small, from the Masons down, are well known and readily distinguished by a badge. And it appears to me there would be no better time to decide on this matter than at the meeting at Atlanta, placing the matter in the hands of a committee with instructions that the badge shall be ready to issue at the fiftieth meeting of the Association, which will occur in 1897 ; and by the way, has there been any movement as yet to decide whether or not the Society shall hold its fiftieth meeting at Philadelphia, the place of its birth? It would be appropriate to do so in many ways, and would be the means of bringing a large number of members to the city and no doubt at the same time adding a large number of new members. Let us hear from other members on this matter of badges.

Irving C. Buatsoell, M.D.

\section{Medical and Surgical History of the War.}

To the Editor:- - Has there been a law passed for printing a new revision on the Medical and Surgical History of the War of the Rebellion which are to be distributed among the profession through the Congressmen in their districts? The Indiana State Board of Health moved for this bill for a new edition at their last meeting.

Answer: The work has not been republished.

\section{BOOK NOTICES.}

Treatise on the Diseases of Infancy and Childhood. By J. LEwis Smith, M.D., Clinical Professor of Diseases of Children in the Bellevue Hospital Medical College, New York. New (8th) edition, thoroughly revised and rewritten and much enlarged. Handsome octavo of 983 pages, with 273 illustra tions and 4 full-page plates. Cloth, $\$ 4.50$; leather, $\$ 5.50$. Lea Brothers \& Co., New York and Philadelphia. 1896.

For more than a quarter of a century Smith's diseases of children has been a standard book of reference, and a textbook. In advanced age, and with ripened judgment, the distinguished author has revised the book, and this eighth edition the reader will find quite up to date. Dr. Smith has always: been a safe counselor and a conservative one. This characteristic is as apparent now as in the early editions. In regard to the Roux antitoxin treatment of diphtheria, after mentioning the established remedies, he says: "The remedies which we have mentioned are in my opinion the most efficacious and safest of those which pharmacy has heretofore furnished, but a new remedy, known as 'antitoxin,' has been so highly extolled by many eminent physicians as a remedy for diphtheria, that this new remedy demands attention if not employment, wherever this fatal malady occurs." The author then quotes at length from Roux's paper at the Buda-Pesth Congress, and gives his statistics. He quotes, p. 378, the favoring statistics of Saw, Turner, Widehofer and Caille, and per contra says: "We can not write so favorably of the use of antitoxin serum in the New York Foundling Asylum. Since a reliable preparation was obtained from the Health Board, 31 cases were inoculated with the serum. The number of units employed varied from 500 to 2,200 . The antitoxin was inserted under the skin on the first day in 12 cases, on the second or third day in 17 cases, and on the fourth or fifth day in 2 cases. Nineteen received the antitoxin once, 9 received it twice and 3 three times. Microscopic examinations revealed the Klebs-Löffler bacillus in all the cases, and the streptococcus in nearly all the cases, so that in all or nearly all the infection was a mixed one. The physicians who observed these cases and witnessed the necropsies and microscopic investigations could not resist the conviction that the broncho-pneumonia of which so many died was due to the streptococcus which was abundant in the lobules, and upon which microbe the antitoxin has little or no effect. Results : Recovered 14, died 17 (14 from broncho-pneumonia and croup). In four or five of the cases the benefit was very marked after the use of the antitoxin. It is seen that statistics thus far are favorable for the antitoxin treatment, but it must be recollected that the type of the microbe disease frequently changes, so that the experience of several years is often necessary to determine the full value of a remedy."

In regard to the treatment of typhoid fever the author holds that it can not be abridged or its course materially changed, and naturally the antiseptic treatment receives little notice. It is curious to see the term "scrofula" still retained in a chapter entirely separated from tuberculosis, but we suppose some vestiges of the past must be retained.

The surgical diseases of children are treated of by Prof. Stephen Smith with the well-known ability of that author, and brought un to date.

A Text=Book upon the Pathogenic Bacteria, for Students of Medicine and Physicians. By Joseph McFarLaNd, M.D., Demonstrator of Pathological Histology, Lecturer on Bacteriology in the Medical Department of the University of Pennsylvania, etc. With 113 illustrations. Cloth, 8vo, pp. 359 . Price $\$ 2.50$. Philadelphia: W. B. Saunders \& Co. Chicago: W. T. Keener, Agent. 1896.

This book, which is well illustrated and carefully printed, is an excellent one; indeed, we can not too strongly commend it. The description of the methods of study of the pathogenic bacteria are set forth with such clearness that even the beginner may feel less reluctance to commence the study of a branch of medical science which has hitherto been considered as a bugbear on account of the difficult technique. There is a vast amount of information, and yet the work is not bulky and there is no mere padding. We might criticise some of the inaccuracies in the historical introductory, but they are not material, as the work is in itself so useful and generally worthy of commendation. In the first place Redi's books, "Generationem Insectorum," “De Ave Diomedea," “Experimenta circa varias Res Naturales," were published in one $18 \mathrm{mo}$ volume, Amsterdam, in 1686. The "experimenta naturalia" were made in 1662. In the frontispiece to the "De Insectis," a female 